\title{
Evaluation of Nanostructured Lipid Carriers Produced with Interesterified Buriti Oil
}

\section{Lívia Viana de Castro Reis ${ }^{*} \oplus$, Karina Magna Leão $\odot$, Paula Speranza'®, Ana Paula Badan Ribeiro² $\odot$, Gabriela Alves Macedo ${ }^{\top} \odot$ and Juliana Alves Macedo ${ }^{1 *}$ (c)}

\section{SUMMARY}

Research background. Extracted from the pulp of an Amazonian fruit, buriti oil is rich in micronutrients with antioxidant properties and high biological value. The few studies available indicate that this oil could be used in a wide range of applications; however, there are no studies that work on the improvement of the characteristics of this oil for commercial application. The enzymatic interesterification is one of the tools available to improve the properties of oils and fats and our recent studies have demonstrated that the lipase could specifically act on buriti oil to produce structured lipids rich in oleic acid, while preserving most of the minor compounds present in this oil. Still looking for ways to expand the applicability of this raw oil, in this work, we are interested in studying the behaviour of this structured oil in nanostructured lipid carriers (NLCs).

Experimental approach. The NLCs were produced with interesterified buriti oil and the stability, droplet size, electrical charge, microstructure, polymorphism and antioxidant activity of the samples were evaluated by oxygen radical absorbance capacity (ORAC) and ferric reducing antioxidant power (FRAP) methods.

Results and conclusions. The results showed that the interesterification formed more unsaturated triacylglycerols (TAGs), and NLCs prepared with interesterified buriti oil had smaller droplets than NLCs with crude buriti oil. Particles remained stable throughout the storage period and NLCs exhibited complex polymorphism with the presence of three crystalline forms. The ORAC value was approx. $23 \%$ higher in nanolipid carries with structured lipids than in the nanolipid carriers with crude buriti oil, and the FRAP value $16 \%$ higher, demonstrating the influence of interesterification on the antioxidant activity of nanocarriers. Thus, NLCs prepared with interesterified buriti oil had small droplets, high stability and antioxidant capacity, and have a potential for nutritional and biological applications.

Novelty and scientific contribution. This research showed that interesterification positively influenced the physicochemical properties of NLCs, producing the oil rich in oleic acid, high stability and antioxidant capacity. Therefore, it may be interesting to use these nanocarriers to obtain efficient carrier systems for future applications.

Key words: buriti oil, enzymatic interesterification, structured lipids, nanocarrier, droplet size, antioxidant activity

\section{INTRODUCTION}

The Amazon region has suitable climatic conditions for a large number of underexploited native and exotic palm trees with interest to the agricultural industry, which can offer a future income source for local people. Buriti palm tree is an example that has high ecological, cultural and economic value, mainly due to its fruits that have valuable oil for the industries. It is estimated that the average annual production of pulp is approx. 0.79 $\mathrm{t} / \mathrm{ha}$ and of oil $17.0 \mathrm{~kg} / \mathrm{ha}$ (1). Extraction by cold pressing yields about $45 \mathrm{~kg}$ of buriti oil from $1000 \mathrm{~kg}$ of ripe fruits, which is considered as valuable resource for cosmetic, food, polymeric and pharmaceutical industry $(2,3)$. It is commonly used by the local population as a healing agent, sunscreen, or for the treatment of burns, prevention of skin ageing, and even as anti-inflammatory and antibiotic agent (3). Buriti oil is rich in micronutrients 
with antioxidant properties and has high biological value. It contains a high concentration of monounsaturated fatty acids and their content is very similar to olive oil; oleic acid is the major component of buriti oil, followed by palmitic acid (4). In addition, the oil is rich in minor compounds, such as carotenoids, tocopherols and sterols (5). Buriti oil is also a source of phenolic compounds (3), which are present in concentrations greater than those commonly found in other vegetable oils.

However, there are no studies that evaluate the improvement in the characteristics of these oils in order to expand their application. The enzymatic interesterification is one of the processes available to improve the properties of these oils and fats. Recent studies from our research group have shown that enzymatic interesterification can improve the biological characteristics of buriti oil, expanding its potential for applications in the development of cosmetic, pharmaceutical and food products with functional and medicinal effects. Speranza et al. (6) subjected the Amazonian buriti oil and murumuru fat to enzymatic interesterification using two lipases in three different enzyme systems. The three enzyme systems were able to catalyze the reaction, but the enzymes showed different specificities, producing interesterified lipids with different properties. The same research group (7) evaluated the antimicrobial potential of emulsions formulated with interesterified Amazonian oils. The results suggested that the interesterification of these oils may be responsible for changes in the physicochemical characteristics of the emulsions, producing droplets with smaller size and greater antimicrobial activity.

In this work, we are interested in studying the behaviour of this structured buriti oil in nanostructured lipid carriers. In recent years, several companies have developed foods and beverages with nutraceutical and functional properties based on the use of special oils, stimulating the emergence of novel carrier systems for lipids with active compounds. For instance, nanostructured lipid carriers (NLCs) have been successfully applied in several areas to improve the solubility, bioavailability and stability of active compounds. NLCs might be an appropriate alternative to deliver structured buriti oil in foods and cosmetics as a functional ingredient and as vehicles or delivery systems for other lipophilic compounds, such as drugs, nutraceuticals, flavourings, antioxidants and antimicrobial agents.

NLCs are composed of a mixture of solid and liquid lipids. The purpose of these formulations is to produce particles in which the oil phase is incorporated into the core of a solid lipid phase. They have high carrying capacity and provide controlled release of the active compounds (8). Thus, NLCs can enhance encapsulation efficiency, active compound binding and physical stability, and may be a valuable option to improve the chemical stability, bioavailability and controlled release of lipophilic compounds in functional foods. NLCs are able to immobilize active compoundswithin the solid lipid matrix, protecting them from degradation (9) by acting as a physical barrier against aqueous phase components.

For all that, we aimed to study the viability of producing NLCs with the structured buriti oil, and the characteristics of these nanoparticles formed with this special oil for future application as delivery systems in food and pharmaceutical industries.

\section{MATERIALS AND METHODS}

\section{Materials}

Crude buriti oil was purchased from Beraca Sabará (São Paulo, SP, Brazil). Compritol 888 ATO (glyceryl behenate, a mixture of mono-, di- and triacylglycerols from behenic acid) was bought from Brasquim (Porto Alegre, RS, Brazil). Immobilized Thermomyces lanuginosus lipase (Lipozyme TL-IM) was obtained from Novozymes Latin America Ltda (Araucária, PR, Brazil). All other reagents and solvents were of analytical grade.

\section{Enzymatic interesterification}

Enzymatic interesterification of buriti oil was performed in an orbital shaking water bath (model TE-0532; Tecnal, Piracicaba, SP, Brazil), for 6 or $24 \mathrm{~h}$ at $150 \mathrm{rpm}$ and $40{ }^{\circ} \mathrm{C}$ using $10 \mathrm{~g}$ of buriti oil and $2.5 \%(\mathrm{~m} / \mathrm{m})$ Lipozyme TL-IM (6). After the reaction was completed, the interesterified oil was immediately filtered through a $0.45-\mu \mathrm{m}$ membrane. The filtrate was purified with $96 \%$ ethanol at $40^{\circ} \mathrm{C}$ to remove free fatty acids. A stream of pure nitrogen was passed through the reaction mixture to prevent fat oxidation and samples were stored in a freezer at $-18^{\circ} \mathrm{C}$.

\section{Structured oil characterization}

\section{Fatty acid composition of buriti oil}

The fatty acid composition of buriti oil was determined by gas chromatography (model GCMS-QP2010S; Shimadzu, Tokyo, Japan), coupled to an FID flame ionization detector according to AOCS method Ce 1-62 (10). Fatty acid methyl esters were separated according to Hartman and Lago's method (11) on Agilent DB-23 (Santa Clara, CA, USA) capillary column ((50\% cyanopropyl)-methylpolysiloxane), $l=60 \mathrm{~m}, d_{\text {int }}=0.25 \mathrm{~mm}, \delta_{\text {film }}=0.25 \mu \mathrm{m}$. The following oven temperature schedule was employed: 110 ${ }^{\circ} \mathrm{C}$ for $5 \mathrm{~min}, 110-215^{\circ} \mathrm{C}\left(5^{\circ} \mathrm{C} / \mathrm{min}\right), 215^{\circ} \mathrm{C}$ for $24 \mathrm{~min}$; detector temperature $280^{\circ} \mathrm{C}$; injector temperature $250^{\circ} \mathrm{C}$, column flow $1.0 \mathrm{~mL} / \mathrm{min}$, linear velocity $24 \mathrm{~cm} / \mathrm{s}$, entrainment gas helium, 1:50 split, injected volume $1.0 \mu \mathrm{L}$. The molar fatty acid composition was calculated using the reference standard for the mixture of fatty acid methyl esters (FAME) obtained from Sigma-Aldrich, Merck (Supelco 37 Component FAME mix, Darmstadt, Germany). FAME were quantified using relative peak areas. Analyses were carried out in duplicate, and the mean and standard deviations of each sample were calculated (12).

\section{Lipid class analysis}

Lipid class (triacylglycerols (TAG), diacylglycerols (DAG), monoacylglycerols (MAG), and free fatty acids) analysis of buriti oil and structured buriti oil was performed by high-performance size exclusion chromatography (HPSEC). The 
samples were diluted to 1:100 in tetrahydrofuran and analyzed in a liquid chromatograph equipped with a Rheodyne 7725i injector and a Waters 510 pump (Waters Associates, Milford, MA, USA) with two Ultrastyragel columns (100 and 500 $\AA$; Waters Associates), each with $25 \mathrm{~cm} \times 0.77 \mathrm{~cm}$ i.d., packed with a styrene-divinylbenzene copolymer $\left(d_{\text {internal }}=10 \mathrm{~mm}\right)$, connected in series, and a refractive index detector (Hewlett Packard, Palo Alto, CA, USA). Conditions were the following: mobile phase tetrahydrofuran (HPLC grade), flow $1 \mathrm{~mL} / \mathrm{min}$, and injection volume $20.0 \mu \mathrm{L}$ (13). The classes of compounds were identified by comparing the elution times with triacylglycerols, diacylglycerols, monoacylglycerols and free fatty acid standards and the analysis was performed in duplicate.

\section{Triacylglycerol composition}

The TAG composition of buriti oil was analyzed by reversed-phase HPLC, following the method described by Holčapek et al. (14) and adapted by Carvalho et al. (15). The chromatographic peaks of the samples were compared with the retention times of chromatographic peaks of soybean oil, which was used as a reference sample (16) and identified based on the expected elution order (considering that retention is increased), and on the fatty acid composition of the samples that were used as a reference. TAG composition of the samples was determined by internal normalization. Analysis was carried out in duplicate.

\section{Determination of tocopherols}

The levels of $\alpha-, \beta-, \gamma$ - and $\delta$-tocopherols were determined according to AOCS method Ce 8-89 (17). Samples were diluted in hexane at a concentration of $0.1 \mathrm{mg} / \mathrm{mL}$ and then injected in UHPLC Ultimate ${ }^{\circledR} 3000$ liquid chromatograph (Dionex, Sunnyvale, CA, USA) with a PerkinElmer (Waltham, MA, USA) Series 200a fluorescence detector (290 nm excitation and 330 $\mathrm{nm}$ emission). The microparticulate silica column $\mathrm{l}=250 \mathrm{~mm}$, $d_{\text {int }}=4 \mathrm{~mm}$, with each particle measuring approx. $5 \mu$ with mobile phase composed of HPLC grade hexane (99\%) and isopropanol (1\%) was used.

The qualitative composition of tocopherols was determined by comparison of peak retention times with those of tocopherol standards ( $\alpha^{-}, \beta-, \gamma^{-}$and $\delta$-tocopherols), and the quantitative composition was determined by normalizing the area under the curve. Analysis was performed in triplicate, and mass fraction of tocopherol in oil samples was expressed in $\mathrm{mg} / \mathrm{kg}$. The conversion to a-tocopherol equivalent unit (a-TE) was obtained through coefficient 1 for a-tocopherol, 0.5 for $\beta$-tocopherol, 0.1 for $\gamma$-tocopherol and 0.03 for $\delta$-tocopherol, according to Darnet et al. (18).

\section{Determination of $\beta$-carotene}

$\beta$-Carotene content was determined spectrophotometrically, according to the method of de França et al. (19). An aliquot of $0.1 \mathrm{~g}$ of oil was diluted in $25 \mathrm{~mL}$ of a 7:3 solvent mixture of $n$-hexane and acetone ( $>99 \%$, Merck, Darmstadt, Germany) and absorbance was read at $453 \mathrm{~nm}$ using a UV-Vis Agilent (Agilent Technologies, Waldbronn, Germany) spectrophotometer. Carotenes in the extracts were calculated in terms of $\beta$-carotene, using a standard absorbance curve calibrated with $\beta$-carotene (>99\%, Merck, Darmstadt, Germany). The standard curve was prepared with $0.1 \mathrm{~g}$ of $\beta$-carotene diluted up to $100 \mathrm{~mL}$ with the $7: 3$ solvent mixture of $n$-hexane and acetone. Aliquots were taken from this solution and diluted to five different concentrations. Absorbance was read at $453 \mathrm{~nm}$. Results are given in $\mu \mathrm{g}$ of $\beta$-carotene per $\mathrm{g}$ of buriti oil. The analysis was performed in triplicate.

\section{Phenolic compound determination}

Phenolic compounds were determined by the Folin-Ciocalteu method, according to Hrncirik and Fritsche (20). This method is based on the reduction of phosphomolybdic and phosphotungstic acids by phenolic hydroxyls, which produces a blue colour. Phenolic compounds were extracted from the oil with a solution of water/methanol 60:40. Folin-Ciocalteu reagent (Sigma-Aldrich, Merck, St. Louis, MO, USA) was added to suitable aliquots of the extracts. After $3 \mathrm{~min}$, a sodium carbonate solution ( $35 \%$ ) was added to the mixture, which was diluted with water to a final volume of $1 \mathrm{~mL}$. Absorbance was measured after $2 \mathrm{~h}$ at $725 \mathrm{~nm}$ on a Shimadzu spectrophotometer UV-1800 (Kyoto, Japan). The blank contained all the constituents of the reaction except phenolic solution, which was substituted by distilled water. A calibration curve was prepared using a standard solution of gallic acid (Sigma-Aldrich, Merck) at concentrations of 0.01-0.1 $\mathrm{\mu g} /$ $\mathrm{mL}$. Analysis was performed in triplicate, and results are expressed in $\mu \mathrm{g}$ of gallic acid equivalents per $\mathrm{g}$ of buriti oil.

\section{Nanostructured lipid carrier preparation}

NLCs were prepared according to the method of Müller et al. (21) and Averina et al. (22). NLC aqueous dispersions containing $10 \%(\mathrm{~m} / \mathrm{m})$ lipid phase were prepared by hot high-pressure homogenization. The lipid phase, composed of a 1:1 ( $\mathrm{m} / \mathrm{m}) \mathrm{mix}-$ ture of solid lipids (Compritol 888 ATO) and buriti oil (non-interesterified, interesterified for $6 \mathrm{~h}$, or interesterified for $24 \mathrm{~h}$ ), was previously heated to $85^{\circ} \mathrm{C}$. The aqueous phase, composed of $1.2 \%$ Tween 80 emulsifier in deionized water, was also previously heated to $85^{\circ} \mathrm{C}$. Then, the lipid phase was added to the aqueous phase under continuous stirring using an Ultra-Turrax T25 (IKA, Staufen, Germany), and the mixture was kept at $85^{\circ} \mathrm{C}$ and $7000 \mathrm{rpm}$ for $5 \mathrm{~min}$. The samples were subsequently homogenized in a high-pressure homogenizer (GEA-Niro-Soavi, Parma, Italy) at $85^{\circ} \mathrm{C}$ and $8 \cdot 10^{4} \mathrm{kPa}$ for 3 cycles. The oil-in-water emulsion was cooled to room temperature to promote the recrystallization of the lipid phase, and thus NLCs were formed (23). NLCs prepared with non-interesterified buriti oil ( $\left.\mathrm{NLC}_{\mathrm{BO}}\right)$, with buriti oil that was interesterified for $6 \mathrm{~h}\left(\mathrm{NLC}_{\mathrm{BO}}{ }_{\mathrm{h}}\right)$, and with buriti oil that was interesterified for $24 \mathrm{~h}\left(\mathrm{NLC}_{\mathrm{BO} 24 \mathrm{~h}}\right)$ were stored at refrigeration $\left(4^{\circ} \mathrm{C}\right)$ and room $\left(25^{\circ} \mathrm{C}\right)$ temperatures. 


\section{NLC characterization}

\section{Droplet size measurement}

The droplet size distribution of NLCs was measured using dynamic light scattering (Mastersizer 2000; Malvern Instruments, Malvern, UK) (24). Results are presented as Z-average particle diameters. The refractive indices of the dispersed and continuous phases used in these calculations were 1.46 and 1.33 , respectively. Analyses were performed in triplicate with all samples: $\mathrm{NLC}_{\mathrm{BO}}, \mathrm{NLC}_{\mathrm{BO} 6 \mathrm{~h}}$ and $\mathrm{NLC}_{\mathrm{BO} 24 \mathrm{~h}}$ after 1,15 and 30 days of storage at refrigeration $\left(4^{\circ} \mathrm{C}\right)$ and room $\left(25^{\circ} \mathrm{C}\right)$ temperatures.

\section{Zeta potential measurement}

Zeta potential (caused by electric charges around droplets) can provide information about interfacial properties. Zeta potential was determined using Zetasizer Nano-ZS equipment (Malvern Instruments) and samples were diluted (1:100) in distilled water (25). Analyses were performed in triplicate with $\mathrm{NLC}_{\mathrm{BO}}, \mathrm{NLC}_{\mathrm{BO} 6 \mathrm{~h}}$ and $\mathrm{NLC}_{\mathrm{BO} 24 \mathrm{~h}}$ after 1,15 and 30 days of storage at refrigeration $\left(4^{\circ} \mathrm{C}\right)$ and room $\left(25^{\circ} \mathrm{C}\right)$ temperatures.

\section{Confocal laser scanning microscopy}

Confocal laser scanning microscopy was carried out using a TCS SP5 II microscope (Leica Microsystems, Heidelberg, Germany). The oil phase of NLCs $(100 \mu \mathrm{L})$ was dyed with 10 $\mu \mathrm{L}$ of Nile Red solution in ethanol ( $1 \mathrm{mg} / \mathrm{mL})$. Samples were mounted on glass slides and examined under $10 x$ and $63 x$ magnification at excitation and emission wavelengths of 543 and $605 \mathrm{~nm}$, respectively. Autofluorescence was analyzed using the built-in software LAS lite (Zeiss Inc., Toronto, Canada) to evaluate the morphology of fat crystals (26). Analyses were performed with $\mathrm{NLC}_{\mathrm{BO}}, \mathrm{NLC}_{\mathrm{BO} 6 \mathrm{~h}}$ and $\mathrm{NLC}_{\mathrm{BO} 24 \mathrm{~h}}$ after 1,15 and 30 days of storage at room $\left(25^{\circ} \mathrm{C}\right)$ temperature.

\section{Polymorphism analysis}

The polymorphic forms of fat crystals were investigated by X-ray diffraction, according to AOCS method Cj 2-95 (27). Analyses were performed using a PW 1710 Philips diffractometer (Malvern Panalytical, Almelo, The Netherlands) with Bragg-Brentano geometry $(\theta: 2 \theta)$ and $\mathrm{Cu}$-Ka radiation $(\lambda=1.54056 \AA)$ at $40 \mathrm{kV}$ and $30 \mathrm{~mA}$. Step sizes of $0.02^{\circ}(2 \theta$ scale $)$ and an acquisition time of $2 \mathrm{~s}$ were used in the scanning range of $5-40^{\circ}$ ( $2 \theta$ scale). Polymorphic forms were identified by the characteristic short spacings of each crystal. Analyses were performed with $\mathrm{NLC}_{\mathrm{BO}}$ and $\mathrm{NLC}_{\mathrm{BO} 24 \mathrm{~h}}$ after 30 and 120 days of storage at room $\left(25^{\circ} \mathrm{C}\right)$ temperature.

\section{Antioxidant activity assay}

Oxygen radical absorbance capacity (ORAC) assay was performed in a 96-well plate (TPP Techno Plastic Products AG, Trasadingen, Switzerland), using fluorescein (Sigma-Aldrich, Merck) as a fluorescent probe, according to the procedures of Dávalos et al. (28). The measurements were performed using a microplate reader (FLUOstar OPTIMA; BMG Labtech, Offenburg, Germany) with fluorescence filters at $485 \mathrm{~nm}$ excitation and $520 \mathrm{~nm}$ emission. The reaction, performed at $37^{\circ} \mathrm{C}$, was started by thermal decomposition of 2,2'-azobis(2-methylpropionamidine) (AAPH; Sigma-Aldrich, Merck, Steinheim, Germany) in a 75-mM phosphate buffer ( $\mathrm{pH}=7.4)$. ORAC values were calculated using the difference between the area under the fluorescein decay curve of the sample and the blank (net area under the curve). Standard curves were constructed using 6-hydroxy-2,5,7,8-tetramethylchroman-2-carboxylic acid (Trolox, Sigma-Aldrich, Merck) at concentrations between 30 and $1500 \mu \mathrm{mol} / \mathrm{mL}$. Regression equations between the net area under the curve and antioxidant concentration were calculated. Final values are expressed in $\mu \mathrm{mol}$ Trolox equivalents (TE) per $\mathrm{mL}$ of dry matter and analyses were performed in triplicate with $\mathrm{NLC}_{\mathrm{BO}}$ and $\mathrm{NLC}_{\mathrm{BO} 24 \mathrm{~h}}$.

\section{Ferric-reducing antioxidant power assay}

FRAP assay was carried out according to Benzie and Strain (29). In the dark environment, aliquots of $30 \mu \mathrm{L}$ of standard or blank samples were added to $90 \mu \mathrm{L}$ of distilled water and $900 \mu \mathrm{L}$ of the FRAP reagent $(2.25 \mathrm{~mL}$ of $0.3 \mathrm{M}$ acetate buffer (Riedel-de Haen, Seelze, Germany), $\mathrm{pH}=3.6,225 \mu \mathrm{L}$ of $10 \mathrm{mM}$ TPTZ (2,4,6-tripyridyl-s-triazine; Fluka Chemicals, Switzerland) in $40 \mathrm{mM} \mathrm{HCl}$ and $225 \mu \mathrm{L}$ of $20 \mathrm{mM}$ iron(III) chloride solution. The mixture was vortexed and $200-\mu \mathrm{L}$ aliquots were transferred to a clear 96-well microplate. Absorbance was read using a microplate reader (FLUOstar OPTIMA; BMG Labtech) at $595 \mathrm{~nm}$ and $37^{\circ} \mathrm{C}$ for $30 \mathrm{~min}$ of reaction. To achieve the standard curve, Trolox ${ }^{\circledR}$ solutions were prepared at concentrations between 15 and $1500 \mu \mathrm{mol} / \mathrm{mL}$. Results are expressed in $\mu \mathrm{mol}$ Trolox equivalents (TE) per $\mathrm{mL}$ of dry matter and analyses were performed in triplicate with $\mathrm{NLC}_{\mathrm{BO}}$ and $\mathrm{NLC}_{\mathrm{BO} 24 \mathrm{~h}}$.

\section{Statistical analysis}

Results are presented as mean value \pm standard deviation of replicates. Results were compared by analysis of variance (ANOVA) using Statistica v. 7.1 (30), and $p<0.05$ was considered to be significant difference between the results.

\section{RESULTS AND DISCUSSION}

\section{Buriti oil characterization}

Before the interesterification reaction, fatty acid composition of buriti oil was analyzed and the interesterification was evaluated through triacylglycerol composition and lipid classes. The complete characterization was published in our earlier report (12). Nevertheless, in this paper, we summarize the most relevant data for the present discussion.

Fatty acid composition analysis showed that the tested buriti oil is rich in oleic (C18:1) (74.2\%) and palmitic acids (C16:0) (19.8\%). The main types of triacylglycerols (TAG) in buriti oil were POO (38.9\%) and OOO (32.7\%). After 
interesterification, there was a reduction in the levels of POO (32.7\%) and an increase in the $\mathrm{OOO}(36.8 \%)$. These modifications affect the functionality of the oil and reduce the melting range, altering lubrication properties, mechanical performance, structure and nutritional properties (31). Lipid class analysis showed that TAG structure was preserved after $24 \mathrm{~h}$ of interesterification. The 24-hour interesterification promoted a small increase (from 6.7 to $9.2 \%$ ) in diacylglycerol, but not the formation of monoacylglycerols or free fatty acids.

Buriti oil contained four tocopherol isomers ( $\alpha, \beta, \gamma$ and $\delta)$ and the $\beta$-isomer $((83.6 \pm 1.8) \mathrm{mg} / \mathrm{kg})$ was predominant in this oil. After $24 \mathrm{~h}$ of interesterification, there was a significant loss $((60.4 \pm 0.9) \mathrm{mg} / \mathrm{kg})$ of this isomer. In a study by Darnet et al. (18), the most abundant fraction was also $\beta$-tocopherol (57 $\mathrm{mg} / \mathrm{kg}$ ). The four tocopherol isomers were also detected in a previous work of our research group (3), but at different levels. Differences in the mass fractions of tocopherol isomers may be caused by the refining conditions of the oil or by the soil and climate conditions under which buriti palm trees are cultivated. In contrast to the observed in relation to tocopherol content, carotenoids were not affected by interesterification, i.e. $\beta$-carotene mass faction in structured buriti oil did not differ from that of the crude oil.

The mass fraction of total phenolics $((292.3 \pm 6.8) \mu \mathrm{g} / \mathrm{g})$ in buriti oil was close to that found in other vegetable oils. After interesterification, total phenolic concentration increased ((329.8 \pm 10.2$) \mu \mathrm{g} / \mathrm{g})$, which was not an expected result. We have previously suggested (12) that this result was a consequence of improved solubilization of structured lipids in the reaction medium. However, further investigations are needed at this point.

\section{Droplet size}

NLCs have been shown to be carriers with great ability to disperse bioactive compounds. The addition of solid lipids to emulsions improves stability and allows greater control of the release of bioactive molecules (22).

In this study, NLCs prepared with interesterified buriti oil had small droplets, especially $\mathrm{NLC}_{\mathrm{BO} 24 \mathrm{~h}}$ sample, which had droplets that were $46 \%$ smaller than those of $\mathrm{NLC}_{\mathrm{BO}}$ (Table 1). This is a very interesting result, under the same process conditions but with the structured oil, we obtained smaller nanocarriers. The TAG modifications from the biotransformation reaction may have influenced the particle size. The interesterification formed more unsaturated TAG (OOO), we believe, exerting a positive effect on NLC droplet size, even after the addition of Compritol 888 ATO to the system. Nanocarriers prepared with non-interesterified oils have larger droplets and are less stable than those prepared with interesterified oils, as their components have different properties (such as viscosity and melting temperature). Interesterification can produce single-phase lipids that do not undergo phase separation, which results in more stable emulsions (32). Furthermore, interesterification can reduce the types of TAGs initially present in the starting oil, thereby forming a lipid phase with a narrower range of polymorphic forms, greater capacity for interaction with other components, and more organized packing (33).

Storage time and temperature did not influence droplet size or stability. The properties of lipid nanoparticles are typically affected by many factors, including type and concentration of lipids and surfactants and viscosity of the lipid phase. It has been reported that particle size increases as the viscosity of the lipid phase increases (34) and that NLCs have smaller droplets when oil is added to the system, as liquid fats reduce lipid phase viscosity and surface tension. In contrast, increased surfactant concentration decreases particle size (35), because surfactants facilitate the fragmentation of nanoparticles during homogenization, reducing surface tension at the interface between solid and liquid phases.

In a study by Walker et al. (36), nanoemulsions were prepared using spontaneous emulsification with $10 \%$ total oil phase ( $50 \%$ fish oil and $50 \%$ lemon oil, by mass) and different surfactant/oil ratio. These nanoparticles were maintained at 5,20 and $37^{\circ} \mathrm{C}$ for 14 days to assess their physical stability. The surfactant concentration also had a large impact on the average particle diameter of the emulsions: as the surfactant/ oil ratio increased, the mean particle diameter decreased. In addition, the mean particle size did not depend strongly on storage time or temperature, as occurred in our study. The fact that there was no significant change in the average particle size of the nanoemulsions after being stored at 5, 20 and $37^{\circ} \mathrm{C}$ for 14 days suggests that they were stable against flocculation, coalescence and Ostwald ripening.

Table 1. Droplet size $(\mathrm{nm})$ of nanostructured lipid carriers after 1, 15 and 30 days of storage at refrigeration $\left(4^{\circ} \mathrm{C}\right)$ and room $\left(25^{\circ} \mathrm{C}\right)$ temperatures

\begin{tabular}{ccccc} 
Temperature $/{ }^{\circ} \mathrm{C}$ & \multicolumn{4}{c}{$d_{32} / \mathrm{nm}$} \\
\cline { 2 - 5 } & $t /$ day & $\mathrm{NLC}_{\text {BO }}$ & $\mathrm{NLC}_{\text {BO6h }}$ & NLC $_{\text {BO24h }}$ \\
\multirow{3}{*}{4} & 1 & $(717.00 \pm 0.01)^{\mathrm{b}}$ & $(524.00 \pm 0.01)^{\mathrm{c}}$ & $(401.00 \pm 0.01)^{\mathrm{d}}$ \\
& 15 & $(729.00 \pm 0.01)^{\mathrm{ab}}$ & $(537.00 \pm 0.01)^{\mathrm{c}}$ & $(393.00 \pm 0.01)^{\mathrm{d}}$ \\
& 30 & $(729.00 \pm 0.03)^{\mathrm{ab}}$ & $(538.00 \pm 0.01)^{\mathrm{c}}$ & $(406.00 \pm 0.01)^{\mathrm{d}}$ \\
25 & 1 & $(748.00 \pm 0.01)^{\mathrm{a}}$ & $(532.00 \pm 0.01)^{\mathrm{c}}$ & $(393.00 \pm 0.01)^{\mathrm{d}}$ \\
& 15 & $(737.00 \pm 0.01)^{\mathrm{ab}}$ & $(530.00 \pm 0.01)^{\mathrm{c}}$ & $(405.00 \pm 0.01)^{\mathrm{d}}$ \\
& 30 & $(744.00 \pm 0.01)^{\mathrm{a}}$ & $(529.00 \pm 0.01)^{\mathrm{c}}$ & $(402.00 \pm 0.01)^{\mathrm{d}}$
\end{tabular}

$\mathrm{NLC}_{\mathrm{BO}}=$ nanostructured lipid carrier prepared with non-interesterified buriti oil,

$\mathrm{NLC}_{\mathrm{BO} 6 \mathrm{~h}}=$ nanostructured lipid carrier prepared with buriti oil interesterified for 6 and $\mathrm{NLC}_{\mathrm{BO} 24 \mathrm{~h}}$ for $24 \mathrm{~h}$. Results are expressed as mean value \pm standard deviation (S.D.); $N=3$. Values followed by different letters in superscript differ significantly $(p \leq 0.05)$ according to Tukey's test 
Yang et al. (37) investigated the effect of different liquid carrier oils on the crystallization and aggregation behaviour of tristearin NLC dispersions. The results demonstrated that NLC suspension stability was strongly affected by the type and amount of the carrier oil. Unsaturated fatty acids and short chain fatty acids result in lower melting points, affecting the stability of NLC dispersions. These results were confirmed by using olive oil (melting point of $-6^{\circ} \mathrm{C}$ ) and palm oil (melting point of $35^{\circ} \mathrm{C}$ ) for the production of nanoparticles. Olive oil is rich in oleic acid, as is buriti oil; this property allowed for a much more stable dispersion than that obtained with palm oil.

\section{Zeta potential of buriti oil droplets}

Zeta potential is a parameter used to evaluate the stability and characteristics of particles. It indicates the electric charge on the surface of nanoparticles as well as the electrostatic repulsion between them. Table 2 shows the $\zeta$-potential of NLCs prepared with buriti oil and structured buriti oil after 1,15 and 30 days of storage at 4 or $25^{\circ} \mathrm{C}$.

A minimum $\zeta$-potential value of $\pm 30 \mathrm{mV}$ is required to prevent coalescence of droplets (38). Interesterification of buriti oil influenced the interfacial properties of droplets under the evaluated conditions. However, although $\mathrm{NLC}_{\mathrm{BO}}$ initially had higher $\zeta$-potential values than $\mathrm{NLC}_{\mathrm{BO} \text { h }}$ and $\mathrm{NLC}_{\mathrm{BO} 24 \mathrm{~h}^{\prime}}$ differences among the $\zeta$-potential values of NLCs became non-significant with storage time, indicating that interesterification helped maintain stability over time. The higher value of $\zeta$-potential, positive or negative, the lower the probability of the droplets coalescing and better their stability (39). Thus, the physical stability of the nanostructured lipid carriers was maintained over time.

All dispersions exhibited negative $\zeta$-potential values, showing that repulsion forces predominated over attraction forces. This property is desirable in NLCs, as it prevents the formation of aggregates and is an indicator of particle stability. NLCs, solid lipid nanoparticles and lipid emulsions also had a negative charge in a study by Fang et al. (40). The negative charge was caused by the anionic fractions of the lipophilic emulsifier (soybean phosphatidylcholine) and the fatty acid glycerides in the lipid core of Compritol and Precirol.
The stability of lipid nanoparticles is affected by the type and concentration of lipids. Niculae et al. (23) used different lipid matrices to prepare NLCs. Carnauba oil was added to the carrier system initially prepared with pomegranate seed oil only, and the $\zeta$-potential increased from -21.7 to -30.9 $\mathrm{mV}$. The components of carnauba oil might have disrupted the surfactant shell, causing a rearrangement of the surface charge and a consequent change in $\zeta$-potential. In addition, the authors found that when oil concentration decreased, the physical stability of nanocarriers slightly increased. In a study by How et al. (41) three different formulations of NLC were prepared, containing olive oil/hydrogenated palm oil (HPO) ratios of 1:9, 2:8 and 3:7 and Polysorbate 80 . These authors observed that increase in the oil to HPO ratio had caused increase in the $\zeta$-potential of the NLC, while the increase in surfactant content decreased particle size.

Surfactants also play an important role in the stabilization of NLC lipid particles. Tween 80 , the surfactant used in this study, is a non-ionic surfactant that provides steric repulsion through which the semi-solid particles of NLCs are stabilized. If the amount of surfactant is not sufficient, some lipid particles might be uncovered, which can lead to flocculation, aggregation and gelling (42). In a study by Niculae et al. (43), lipid nanoparticles prepared with Tween 80 as the main surfactant had better physical stability than those prepared with Tween 20, showing the importance of surfactants for nanoparticle stability. Thus, interesterification of buriti oil might have allowed for a better interaction between emulsifier and oil, providing greater stability.

\section{Morphology of nanostructured lipid carriers}

As storage temperature did not affect particle stability, microscopic analysis was not performed with samples stored under refrigeration. Fig. 1 shows the morphology of NLCs after 1, 15 and 30 days of storage at room temperature.

The confocal microscopy images (Fig. 1) show individual droplets with a spherical shape. In general, NLCs had a relatively wide droplet size range and droplets were polydisperse, without uniformity. The distribution of $\mathrm{NLC}_{\mathrm{BO}}$ droplets was more homogeneous up to 15 days of storage, but droplets were more agglomerated after 30 days than those

Table 2. Zeta potential of nanostructured lipid carriers after 1, 15 and 30 days of storage at refrigeration $\left(4^{\circ} \mathrm{C}\right)$ and $\operatorname{room}\left(25^{\circ} \mathrm{C}\right)$ temperatures

\begin{tabular}{|c|c|c|c|c|}
\hline \multirow{2}{*}{ Temperature $/{ }^{\circ} \mathrm{C}$} & \multirow{2}{*}{$t /$ day } & \multicolumn{3}{|c|}{$\zeta$-potential/mV } \\
\hline & & $\mathrm{NLC}_{\mathrm{BO}}$ & $\mathrm{NLC}_{\text {Boбh }}$ & $\mathrm{NLC}_{\mathrm{BO24h}}$ \\
\hline \multirow{3}{*}{4} & 1 & $(-26.1 \pm 0.7)^{\mathrm{def}}$ & $(-24.8 \pm 0.6)^{\mathrm{abcde}}$ & $(-23.1 \pm 0.6)^{\mathrm{a}}$ \\
\hline & 15 & $(-26.0 \pm 0.2)^{\text {cde }}$ & $(-25.6 \pm 0.3)^{\text {bcde }}$ & $(-23.9 \pm 0.1)^{\mathrm{ab}}$ \\
\hline & 30 & $(-26.2 \pm 0.5)^{\mathrm{def}}$ & $(-26.0 \pm 0.2)^{\mathrm{cde}}$ & $(-24.0 \pm 0.6)^{\mathrm{abc}}$ \\
\hline \multirow{3}{*}{25} & 1 & $(-28.1 \pm 1.0)^{\mathrm{fg}}$ & $(-24.5 \pm 0.3)^{\mathrm{abcd}}$ & $(-23.5 \pm 0.6)^{\mathrm{a}}$ \\
\hline & 15 & $(-26.7 \pm 1.3)^{\mathrm{ef}}$ & $(-24.6 \pm 0.9)^{\mathrm{abcd}}$ & $(-24.7 \pm 0.3)^{\mathrm{abcd}}$ \\
\hline & 30 & $(-24.8 \pm 0.6)^{\mathrm{abcde}}$ & $(-29.3 \pm 0.9)^{9}$ & $(-24.6 \pm 0.9)^{\mathrm{abcd}}$ \\
\hline
\end{tabular}

$\mathrm{NLC}_{\mathrm{BO}}=$ nanostructured lipid carrier prepared with non-interesterified buriti oil,

$\mathrm{NLC}_{\mathrm{BOGh}}=$ nanostructured lipid carrier prepared with buriti oil interesterified for 6 and

$\mathrm{NLC}_{\mathrm{BO} 24 \mathrm{~h}}$ for $24 \mathrm{~h}$. Results are expressed as mean value \pm S.D. $(N=3)$. Mean values followed

by different letters differ significantly $(p \leq 0.05)$ according to Tukey's test 

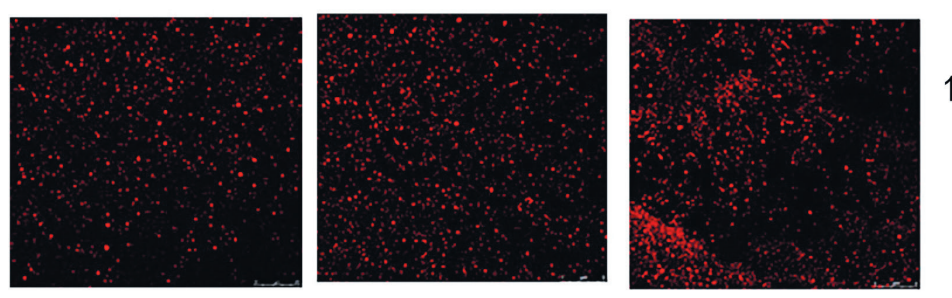

t/day
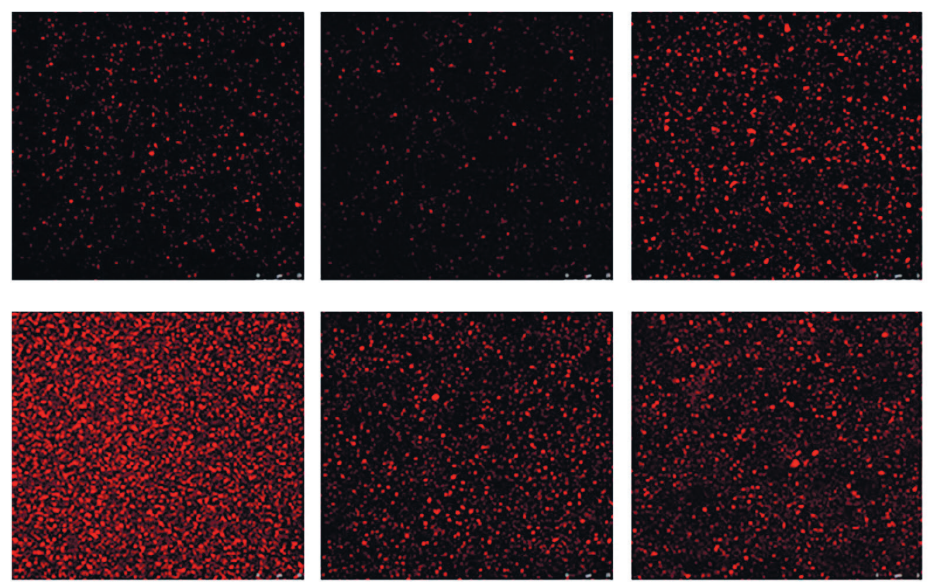

$\mathrm{NLC} \mathrm{BO}_{\mathrm{O}}$

NLCBo6h

NLCBO24h

Fig. 1. Influence of oil type on the morphology of nanostructured lipid carriers (NLCs). The oil phase is stained red, the scale bar is $25 \mu \mathrm{m}$. NLC $\mathrm{BO}_{\mathrm{BO}}=$ nanostructured lipid carrier prepared with non-interesterified buriti oil, $\mathrm{NLC}_{\mathrm{BO} O \mathrm{~h}}=$ nanostructured lipid carrier prepared with buriti oil interesterified for 6 and $\mathrm{NLC}_{\mathrm{BO} 24 \mathrm{~h}}$ for $24 \mathrm{~h}$

of other NLCs. NLC ${ }_{\mathrm{BO} \text { h }}$ showed a similar behaviour, but droplet aggregation was lower than that of $\mathrm{NLC}_{\mathrm{BO}}$ after 30 days of storage. In contrast, $\mathrm{NLC}_{\mathrm{BO} 24 \mathrm{~h}}$ had a more heterogeneous structure, exhibiting droplet aggregation throughout the storage period (44). Wegmüller et al. (45) reported the occurrence of particle agglomerates and fat crystals in the microcapsules developed in their study. Agglomeration might have occurred because microparticles were not completely solidified when cooled. The authors observed that small particles showed fewer fat crystals on the surface than larger ones, as small particles require less time to be totally solidified.

Different NLC morphologies are observed when using different microscopes, and these morphological discrepancies might be attributed to the type of lipid and surfactant or the method used to develop NLCs. Many studies suggest that incorporation of bioactive compounds into a solid lipid matrix can improve controlled release, charge, and physical and chemical stability by disrupting the crystal packing structure (21).

\section{Polymorphism of nanostructured lipid carriers}

TAGs occur in three crystalline forms, $\alpha, \beta^{\prime}$ and $\beta$, which differ in the arrangement of fatty acids. X-ray diffraction analysis was performed to investigate the arrangement of fatty acid chains and identify the polymorphism of crystals by determining the dimensions of the crystal unit and sub-cells. Polymorphs diffract X-rays at different angles as a result of their different geometric configurations, and a diffraction at wide angles corresponds to short spacings (distances between parallel acyl groups in TAG) of sub-cells, which allows the characterization of different polymorphs in fats (46).

The short spacings and polymorphic forms of $\mathrm{NLC}_{\mathrm{BO}}$ and $\mathrm{NLC}_{\mathrm{BO} 24 \mathrm{~h}}$ are presented in Table 3. NLCs show a complex polymorphism as a result of $\beta^{\prime}$ fusion and solid lipid recrystallization. This behaviour can be explained by the nanosize of NLC particles, which cause slower transition to a stable state, and may also be related to the presence of DAG above $5 \%$ in crude and interesterified buriti oil (12), favoring the formation of $\beta^{\prime}$ polymorph. In addition, interesterification reduced TAG melting range, forming more unsaturated fatty acids and causing changes to crystal morphology and polymorphic forms. TAGs usually crystallize first in $a$ and $\beta^{\prime}$ forms even though $\beta$ form is more stable. Factors such as cooling rate, crystallization heat, agitation level, and nanocarrier composition can affect the number and type of crystals. However, if fats are complex mixtures of TAGs, different polymorphic forms and liquid oil can coexist at a certain temperature (47).

Solid lipids are predominantly found in the stable $\beta$-modification. When incorporated into lipid nanoparticles, the lipid transforms into the less ordered, metastable $\beta^{\prime}$-modification, causing a distortion in the crystalline structure (48). 
Table 3. Short spacings (distance between parallel acyl groups in the triacylglycerol) and polymorphic (crystalline) forms of buriti oil, Compritol 888 ATO, NLC ${ }_{\mathrm{BO}}$ and $\mathrm{NLC}_{\mathrm{BO} 24 \mathrm{~h}}$ after 30 and 120 days of storage at $25^{\circ} \mathrm{C}$

\begin{tabular}{|c|c|c|c|c|c|c|c|c|c|}
\hline \multirow{2}{*}{ Sample } & \multirow{2}{*}{ t/day } & \multicolumn{7}{|c|}{ Short spacing (Å) } & \multirow{2}{*}{ Polymorphic form } \\
\hline & & 4.6 & 4.4 & 4.3 & 4.2 & 3.9 & 3.8 & 3.7 & \\
\hline Buriti oil & & & $4.38^{3}$ & & $4.19^{3}$ & $3.92^{3}$ & & & $a+\beta^{\prime}+\beta$ \\
\hline Compritol 888 ATO & & & & & $4.25^{4}$ & & $3.82^{1}$ & & $\beta^{\prime}$ \\
\hline $\mathrm{NLC}_{\mathrm{BO}}$ & 30 & $4.68^{3}$ & $4.45^{3}$ & & $4.23^{3}$ & $3.95^{3}$ & & & $a+\beta^{\prime}+\beta$ \\
\hline $\mathrm{NLC}_{\mathrm{BO24h}}$ & 30 & $4.55^{3}$ & & $4.32^{3}$ & $4.15^{3}$ & & $3.88^{3}$ & & $a+\beta^{\prime}+\beta$ \\
\hline $\mathrm{NLC}_{\mathrm{BO}}$ & 120 & $4.67^{3}$ & $4.46^{3}$ & & $4.18^{3}$ & $3.93^{3}$ & & $3.71^{2}$ & $a+\beta^{\prime}+\beta$ \\
\hline $\mathrm{NLC}_{\mathrm{BO24h}}$ & 120 & $4.63^{3}$ & $4.41^{3}$ & & $4.19^{3}$ & & $3.88^{3}$ & $3.68^{2}$ & $a+\beta^{\prime}+\beta$ \\
\hline
\end{tabular}

$\mathrm{NLC}_{\mathrm{B}}=$ nanostructured lipid carrier prepared with non-interesterified buriti oil, $\mathrm{NLC}_{\mathrm{BO24h}}=$ nanostructured lipid carrier prepared with buriti oil interesterified for $24 \mathrm{~h} .{ }^{1}$ weak, ${ }^{2}$ medium, ${ }^{3}$ strong, ${ }^{4}$ very strong

Previous study demonstrated that the incorporation of lipids in NLCs leads to slower polymorphic transition and lower polydispersity index (49). In addition, NLC crystallization, melting temperatures and polymorphic content have been shown to be strongly dependent on the amount of oil. Jenning et al. (50) prepared NLCs with glyceryl behenate (Compritol 888 ATO) as the solid lipid and caprylic/capric triglycerides (Miglyol 812) as the liquid lipid. NLC dispersions were most stable in the absence of oil and at high concentrations of oil. Other studies showed that the addition of oil to solid lipid nanoparticles did not disrupt the structure of lipid crystals, contrary to the expected $(49,51)$. Given the contradictory results, the effect of oil type on NLC polymorphic behaviour and morphology is still poorly understood (21).

\section{Antioxidant activity of nanostructured lipid carriers}

The ORAC assay measures the ability of an antioxidant to sequester free radicals through the donation of hydrogen atoms. Pulido et al. (52) described the FRAP method as an alternative to determine the ferric reducing capacity of biological fluids and aqueous solutions of pure compounds. These two assays are of great importance because they indicate the antioxidant action in foods and physiological systems.

Table 4 shows the results of the ORAC and FRAP assays. In both assays, $\mathrm{NLC}_{\mathrm{BO} 24 \mathrm{~h}}$ had the highest antioxidant activity. $\mathrm{NLC}_{\mathrm{BO} 24 \mathrm{~h}}$ had approx. $23 \%$ higher ORAC value and $16 \%$ higher FRAP value than $\mathrm{NLC}_{\mathrm{BO}}$, demonstrating the influence of interesterification on the antioxidant activity of nanocarriers. Although there was a significant loss of tocopherols after $24 \mathrm{~h}$ of interesterification, the concentration of $\beta$-carotene was not affected and the concentrations of OOO-TAG (12.5\%) and phenolic compounds increased, which could explain the increase in antioxidant activity (12). In addition, it can be considered that larger particles, such as $\mathrm{NLC}_{\mathrm{BO}}$, tend to generate imperfect, amorphous crystals and can expel bioactive compounds, which causes a lower antioxidant capacity of these samples (53).

Haeiwa et al. (54) reported that unsaturated fatty acids, particularly oleic acid, increase the intracellular levels of lipid peroxidation products, indicating that oleic acid can promote adaptive response and protect cells against oxidative stress-related injury. Buriti oil contains considerable amounts of carotenoids, tocopherols, and phenolic compounds, which give it an important antioxidant power, favouring its own conservation and contributing to the treatment of oxidative stress-related diseases (18).

In a previous study carried out by our research group, the antioxidant capacity was also higher of the structured lipids produced with Lipozyme TL-IM and enzyme from Rhizopus sp., respectively, followed by pure buriti oil. This result indicates that enzymatic interesterification significantly increased the antioxidant capacity of the oil, independently of the content of minor compounds (55). In a study by Poyato et al. (56), the antioxidant capacity expressed as Trolox equivalents, measured by the L-ORAC (lipophilic radical absorption capacity of oxygen) assay, of linseed oil emulsions $(8315.4 \mu \mathrm{mol} / 100 \mathrm{~g})$ was higher than those of NLCs developed in the present study, whereas for olive oil emulsions (1978.9 $\mu \mathrm{mol} / 100 \mathrm{~g}$ ) was similar to those of NLCs. These data suggest that the antioxidant capacity of emulsions differs according to oil type and antioxidant compound.

The antioxidant activity of bioactive compounds is associated with the inhibition of free-radical chain initiation by oxygen binding or chelation of catalytic metal ions to retard

Table 4. ORAC value, linearity (area under curve vs concentration) and FRAP value of $\mathrm{NLC}_{\mathrm{BO}}$ and $\mathrm{NLC}_{\mathrm{BO} 24 \mathrm{~h}}$

\begin{tabular}{|c|c|c|c|c|c|c|}
\hline \multirow{3}{*}{ Sample } & \multicolumn{5}{|c|}{ ORAC assay } & \multirow{3}{*}{$\begin{array}{c}\text { FRAP assay } \\
\text { FRAP } c(\text { TE }) /(\mu \mathrm{mol} / \mathrm{mL})\end{array}$} \\
\hline & \multirow{2}{*}{ ORAC $c(T E) /(\mu \mathrm{mol} / \mathrm{mL})$} & \multirow{2}{*}{$\gamma($ sample $) /(\mathrm{mg} / \mathrm{mL})$} & \multicolumn{3}{|c|}{ Linearity } & \\
\hline & & & Slope & Intercept & $r^{2}$ & \\
\hline $\mathrm{NLC}_{\mathrm{BO}}$ & $(1223.2 \pm 38.8)^{\mathrm{a}}$ & $0.2-0.05$ & 47.41 & 3.045 & 0.99 & $(939.6 \pm 53.0)^{\mathrm{a}}$ \\
\hline $\mathrm{NLC}_{\mathrm{BO24h}}$ & $(1592.4 \pm 94.9)^{\mathrm{a}}$ & $0.2-0.05$ & 53.52 & 3.489 & 0.98 & $(1116.1 \pm 11.5)^{\mathrm{a}}$ \\
\hline
\end{tabular}

$\mathrm{ORAC}=$ oxygen radical absorbance capacity, $\mathrm{TE}=$ trolox equivalents, $\mathrm{NLC}_{\mathrm{BO}}=$ nanostructured lipid carrier prepared with non-interesterified buriti oil, $\mathrm{NLC}_{\mathrm{BO} 24 \mathrm{~h}}=$ nanostructured lipid carrier prepared with buriti oil interesterified for $24 \mathrm{~h}$. Results are expressed as mean value $\pm S$. $D$. ( $N=3$ ). Values followed by different letters in superscript are significantly different at $p<0.05$ 
oxidation and peroxide decomposition, prevent continuous hydrogen abstraction, and protect DNA, proteins and lipids against oxidative damage (3). The results of this study suggest that nanocarriers prepared with interesterified buriti oil can be used in several applications for the improvement of health, including cosmetic formulations, food products and pharmaceuticals.

\section{CONCLUSIONS}

Interesterification reaction time significantly influenced particle size and interfacial properties of nanostructured lipid carriers (NLC). NLCs prepared with interesterified buriti oil formed more unsaturated TAGs and had smaller droplets than NLCs prepared with non-interesterified buriti oil. Although interesterification of buriti oil influenced the interfacial properties of droplets under the evaluated conditions, particles remained stable throughout the storage period. Besides that, NLCs showed a complex polymorphism with the presence of three crystalline forms and NLCs containing structured buriti oil had higher antioxidant capacity determined by ORAC and FRAP assays than NLCs without structured lipids. This research showed that interesterification positively influenced the physicochemical properties of NLCs, producing oils rich in oleic acid, with high stability and antioxidant capacity. Therefore, it may be interesting to use these nanocarriers to obtain efficient carrier systems for future applications.

\section{FUNDING}

The authors acknowledge the financial support received from the Coordination for the Improvement of Higher Education Personnel (CAPES), the National Council for Scientific and Technological Development (CNPq), and the São Paulo Research Foundation (FAPESP, grant no. 2014/16530-1).

\section{CONFLICT OF INTERESTS}

The authors declare that they have no conflict of interests.

\section{AUTHORS' CONTRIBUTION}

L.V.C. Reis participated in designing and performing experiments, processing and interpreting data, as well as in preparation, writing and revising the manuscript. K.M. Leão assisted in designing and performing experiments, processing and interpreting data, and revising the manuscript. P. Speranza also participated in designing and performing experiments, and processing and interpreting data. A.P.B. Ribeiro was involved in designing and performing experiments, and processing and interpreting data. G.A. Macedo designed and performed experiments, and processed and interpreted data. J.A. Macedo also designed and performed experiments, processed and interpreted data, and prepared and revised the manuscript.

\section{ORCID ID}

L.V.C. Reis (1) https://orcid.org/0000-0003-3819-8393

K.M. Leão @ https://orcid.org/0000-0003-0750-8432

P. Speranza (ㄴ) https://orcid.org/0000-0003-4403-3720

A.P.B. Ribeiro (1) https://orcid.org/0000-0002-6532-1265

G.A. Macedo (1) https://orcid.org/0000-0001-5255-2243

J.A. Macedo (1) https://orcid.org/0000-0001-7504-8111

\section{REFERENCES}

1. Cunha MAE, Neves RF, Souza JNS, França LF, Araújo ME, Brunner G, Machado NT. Supercritical adsorption of buriti oil (Mauritia flexuosa Mart.) in $\gamma$-alumina: A methodology for the enriching of anti-oxidants. J Supercrit Fluids. 2012;66:181-91.

https://doi.org/10.1016/j.supflu.2011.10.021

2. Silva SM, Sampaio KA, Taham T, Rocco SA, Ceriani R, Meirelles AJA. Characterization of oil extracted from buriti fruit (Mauritia flexuosa) grown in the Brazilian Amazon region.J Am Oil Chem Soc. 2009;86(7):611-6.

https://doi.org/10.1007/s11746-009-1400-9

3. Speranza P, Falcão ADO, Macedo JA, daSilva LHM. Amazonian buriti oil: Chemical characterization and antioxidant potential. Grasas Aceites. 2016;67(2):e135.

https://doi.org/10.3989/gya.0622152

4. Lunn J. Monounsaturates in the diet. Nutr Bull. 2007;32 (4):378-91.

https://doi.org/10.1111/j.1467-3010.2007.00669.x

5. Santos MFG, Alves RE, Ruíz-Méndez MV. Minor components in oils obtained from Amazonian palm fruits. Grasas Aceites. 2013;64(5):531-6.

https://doi.org/10.3989/gya.048913

6. Speranza P, Ribeiro APB, Macedo GA. Application of lipases to regiospecific interesterification of exotic oils from an Amazonian area. J Biotechnol. 2016;218:13-20.

https://doi.org/10.1016/j.jbiotec.2015.11.025

7. Speranza P, Badan Ribeiro AP, Cunha RL, Macedo JA, Macedo GA. Influence of emulsion droplet size on antimicrobial activity of interesterified Amazonian oils. LWT - Food Sci Technol. 2015;60(1):207-12.

https://doi.org/10.1016/j.lwt.2014.07.022

8. Varshosaz J, Eskandari S, Tabakhian M. Production and optimization of valproic acid nanostructured lipid carriers by the Taguchi design. Pharm Dev Technol. 2010;15(1):89-96. https://doi.org/10.3109/10837450903013568

9. Pardeike J, Hommoss A, Müller RH. Lipid nanoparticles (SLN, NLC) in cosmetic and pharmaceutical dermal products. Int J Pharm. 2009;366(1-2):170-84.

https://doi.org/10.1016/J.IJPHARM.2008.10.003

10. AOCS Official Method Ce 1-62. Fatty acid composition by gas chromatograpy. Urbana, IL, USA: AOCS; 2009.

11. Hartman L, Lago RCA. Rapid preparation of fatty acid methyl esters from lipids. Lab Pract. 1973;22(6):475-6. 
12. Speranza P, Leão KMM, Gomes TSN, Reis LVC, Rodrigues AP, Macedo JA, et al. Improving the chemical properties of Buriti oil (Mauritia flexuosa L.) by enzymatic interesterification. Grasas Aceites. 2018;69(4):e282.

https://doi.org/10.3989/gya.0229181

13. Guedes AMM, Ming CC, Ribeiro APB, da Silva RC, Gioielli LA, Gonçalves LAG. Physicochemical properties of interesterified blends of fully hydrogenated Crambe abyssinica oil and soybean oil. J Am Oil Chem Soc. 2014;91(1):111-23.

https://doi.org/10.1007/s11746-013-2360-7

14. Holčapek M, Lísa M, Jandera P, Kabátová N. Quantitation of triacylglycerols in plant oils using HPLC withAPCI-MS, evaporative light-scattering, and UV detection. J Sep Sci. 2005;28(12):1315-33.

https://doi.org/10.1002/jssc.200500088

15. Carvalho AGA, Silva KA, Silva LO, Costa AM, Akil E, Coelho MA, Torres AG. Jussara berry (Euterpe edulis M.) oil-in-water emulsions are highly stable: The role of natural antioxidants in the fruit oil. J Sci Food Agric. 2019;99(1):90-9.

https://doi.org/10.1002/jsfa.9147

16. AOCS Official Method Ce 5b-89. Triglycerides in vegetable oils by HPLC. Urbana, IL, USA: AOCS; 2017.

17. AOCS Official Method Ce 8-89. Determination of tocopherols and tocotrienols in vegetable oils and fats by HPLC. Urbana, IL, USA: AOCS; 2017.

18. Darnet SH, da Silva LHM, Rodrigues AMC, Lins RT. Nutritional composition, fatty acid and tocopherol contents of buriti (Mauritia flexuosa) and patawa (Oenocarpus bataua) fruit pulp from the Amazon region. Food Sci Technol. 2011;31(2):488-91.

https://doi.org/10.1590/S0101-20612011000200032

19. de França LF, Reber G, Meireles MAA, Machado NT, Brunner G. Supercritical extraction of carotenoids and lipids from buriti (Mauritia flexuosa), a fruit from the Amazon region. J Supercrit Fluids. 1999;14(3):247-56.

https://doi.org/10.1016/S0896-8446(98)00122-3

20. Hrncirik K, Fritsche S. Comparability and reliability of different techniques for the determination of phenolic compounds in virgin olive oil. Eur J Lipid Sci Technol. 2004;106(8):540-9.

https://doi.org/10.1002/ejlt.200400942

21. Müller RH, Radtke M, Wissing SA. Solid lipid nanoparticles (SLN) and nanostructured lipid carriers (NLC) in cosmetic and dermatological preparations. Adv Drug Deliver Rev. 2002;54(Suppl. 1):S131-55.

https://doi.org/10.1016/S0169-409X(02)00118-7

22. Averina ES, Seewald G, Müller RH, Radnaeva LD, Popov DV. Nanostructured lipid carriers (NLC) on the basis of Siberian pine (Pinus sibirica) seed oil. Pharmazie. 2010;65(1):25-31.

23. Niculae G, Lacatusu I, Badea N, Meghea A, Stan R. Influence of vegetable oil on the synthesis of bioactive nanocarriers with broad spectrum photoprotection. Cent Eur J Chem.
2014;12(8):837-50.

https://doi.org/10.2478/s11532-014-0503-9

24. Sato ACK, Moraes KEFP, Cunha RL. Development of gelled emulsions with improved oxidative and $\mathrm{pH}$ stability. Food Hydrocoll. 2014;34:184-92.

https://doi.org/10.1016/j.foodhyd.2012.10.016

25. Averina ES, Müller RH, Popov DV, Radnaeva LD. Physical and chemical stability of nanostructured lipid drug carriers (NLC) based on natural lipids from Baikal region (Siberia, Russia). Pharmazie. 2011;66(5):348-56.

26. Chen F, Liang L, Zhang Z, Deng Z, Decker EA, McClements DJ. Inhibition of lipid oxidation in nanoemulsions and filled microgels fortified with omega-3 fatty acids using casein as a natural antioxidant. Food Hydrocoll. 2017;63:240-8. https://doi.org/10.1016/j.foodhyd.2016.09.001

27. AOCS Official Method Cj 2-95. X-ray diffraction analysis of fats. Urbana, IL, USA: AOCS; 2017.

28. Dávalos A, Gómez-Cordovés C, Bartolomé B. Extending applicability of the oxygen radical absorbance capacity (ORAC-fluorescein) assay. J Agric Food Chem. 2004;52(1):48-54.

https://doi.org/10.1021/jf0305231

29. Benzie IFF, Strain JJ. The ferric reducing ability of plasma (FRAP) as a measure of "antioxidant power": The FRAP assay. Anal Biochem. 1996;239(1):70-6.

https://doi.org/10.1006/abio.1996.0292

30. Statistica Data Analysis Software System, v. 7.1, StatSoft Inc., Hamburg, Germany; 2005.

31. O'Brien RD. Fats and oils: Formulating and processing for applications. Boca Raton, FL, USA: CRC Press; 2009.

32. Grimaldi R, Gonçalves LAG, Gioielli LA, Simões IS. Interactions in interesterified palm and palm kernel oils mixtures. I-Solid fat content and consistency. Grasas Aceites. 2001;52(6):349-54.

https://doi.org/10.3989/gya.2001.v52.i6.341

33. Metin S, Hartel RW. Crystallization of fats and oils. In: Shahidi F, editor. Bailey's industrial oil and fat products edible oil and fat products: Chemistry, properties, and health effects. Chicester, UK: Wiley-Blackwell; 2005. pp. 45-76. https://doi.org/10.1002/047167849X.bio021

34. Ramteke KH, Joshi SA, Dhole SN. Solid lipid nanoparticle: A review. IOSR J Pharm. 2012;2(6):34-44. https://doi.org/10.9790/3013-26103444

35. Bakshi MS, Kaura A, Kaur G, Torigoe K, Esumi K. Effect of sodium dodecylsulfate and dodecyltrimethyl ammonium bromide on the morphologies of gold nanoparticles in the presence of poly(amidoamine) dendrimers. J Nanosci Nanotechnol. 2006;6(3):644-50.

https://doi.org/10.1166/jnn.2006.123

36. Walker RM, Decker EA, McClements DJ. Physical and oxidative stability of fish oil nanoemulsions produced by spontaneous emulsification: Effect of surfactant concentration 
and particle size. J Food Eng. 2015;164:10-20.

https://doi.org/10.1016/j.jfoodeng.2015.04.028

37. Yang $Y$, Corona A, Schubert B, Reeder R, Henson MA. The effect of oil type on the aggregation stability of nanostructured lipid carriers. J Colloid Interface Sci. 2014;418:261-72. https://doi.org/10.1016/j.jcis.2013.12.024

38. Yin LJ, Chu BS, Kobayashi I, Nakajima M. Performance of selected emulsifiers and their combinations in the preparation of $\beta$-carotene nanodispersions. Food Hydrocoll. 2009;23(6):1617-22.

https://doi.org/10.1016/j.foodhyd.2008.12.005

39. Rebolleda S, Sanz MT, Benito JM, Beltrán S, Escudero I, González San-José ML. Formulation and characterisation of wheat bran oil-in-water nanoemulsions. Food Chem. 2015;167:16-23.

https://doi.org/10.1016/j.foodchem.2014.06.097

40. Fang YP, Lin YK, Su YH, Fang JY. Tryptanthrin-loaded nanoparticles for delivery into cultured human breast cancer cells, MCF7: The effects of solid lipid/liquid lipid ratios in the inner core. Chem Pharm Bull (Tokyo). 2011;59(2):266-71. https://doi.org/10.1248/cpb.59.266

41. How CW, Rasedee A, Abbasalipourkabir R. Characterization and cytotoxicity of nanostructured lipid carriers formulated with olive oil, hydrogenated palm oil, and polysorbate 80. IEEE Trans Nanobioscience. 2013;12(2):72-8. https://doi.org/10.1109/TNB.2012.2232937

42. Huang J, Wang Q, Li T, Xia N, Xia Q. Nanostructured lipid carrier (NLC) as a strategy for encapsulation of quercetin and linseed oil: Preparation and in vitro characterization studies. J Food Eng. 2017;215:1-12.

https://doi.org/10.1016/j.jfoodeng.2017.07.002

43. Niculae G, Lacatusu I, Badea N, Meghea A. Lipid nanoparticles based on butyl-methoxydibenzoylmethane: in vitro UVA blocking effect. Nanotechnology. 2012;23(31):315704. https://doi.org/10.1088/0957-4484/23/31/315704

44. Müller RH, Mäder K, Gohla S. Solid lipid nanoparticles (SLN) for controlled drug delivery - A review of the state of the art. Eur J Pharm Biopharm. 2000;50(1):161-77. https://doi.org/10.1016/S0939-6411(00)00087-4

45. Wegmüller R, Zimmermann MB, Bühr VG, Windhab EJ, Hurrell RF. Development, stability, and sensory testing of microcapsules containing iron, iodine, and vitamin A for use in food fortification. J Food Sci. 2006;71(2):S181-7. https://doi.org/10.1111/j.1365-2621.2006.tb08923.x

46. Campos R. Experimental methodology. In: Marangoni AJ, editor. Fat crystal networks. New York, NY, USA: Marcel Dekker; 2005. pp. 267-349.

47. Ribeiro APB, Masuchi MH, Miyasaki EK, Domingues MAF, Stroppa VLZ, de Oliveira GM, Kieckbusch TG. Crystallization modifiers in lipid systems. J Food Sci Technol.
2015;52:3925-46.

https://doi.org/10.1007/s13197-014-1587-0

48. Zimmermann E, Souto EB, Müller RH. Physicochemical investigations on the structure of drug-free and drug-loaded solid lipid nanoparticles (SLN) by means of DSC and $1 \mathrm{H}$ NMR. Pharmazie. 2005;60(7):508-13.

49. Jores K, Mehnert W, Drechsler M, Bunjes H, Johann C, Mäder K. Investigations on the structure of solid lipid nanoparticles (SLN) and oil-loaded solid lipid nanoparticles by photon correlation spectroscopy, field-flow fractionation and transmission electron microscopy. J Control Release. 2004;95(2):217-27.

https://doi.org/10.1016/j.jconrel.2003.11.012

50. Jenning V, Thünemann AF, Gohla SH. Characterisation of a novel solid lipid nanoparticle carrier system based on binary mixtures of liquid and solid lipids. Int J Pharm. 2000;199(2):167-77. https://doi.org/10.1016/S0378-5173(00)00378-1

51. Jores K, Mehnert W, Mäder K. Physicochemical investigations on solid lipid nanoparticles and on oil-loaded solid lipid nanoparticles: A nuclear magnetic resonance and electron spin resonance study. Pharm Res. 2003;20(8):1274-83.

https://doi.org/10.1023/A:1025065418309

52. Pulido R, Bravo L, Saura-Calixto F. Antioxidant activity of dietary polyphenols as determined by a modified ferric reducing/antioxidant power assay. J Agric Food Chem. 2000;48(8):3396-402.

https://doi.org/10.1021/jf9913458

53. Katouzian I, Faridi Esfanjani A, Jafari SM, Akhavan S. Formulation and application of a new generation of lipid nano-carriers for the food bioactive ingredients. Trends Food SciTechnol. 2017;68:14-25. https://doi.org/10.1016/j.tifs.2017.07.017

54. Haeiwa H, Fujita T, Saitoh Y, Miwa N. Oleic acid promotes adaptability against oxidative stress in 3T3-L1 cells through lipohormesis. Mol Cell Biochem. 2014;386:73-83. https://doi.org/10.1007/s11010-013-1846-9

55. Falcão AO, Speranza P, Ueta T, Martins IM, Macedo GA, Macedo JA. Antioxidant potential and modulatory effects of restructured lipids from the Amazonian palms on liver cells. Food Technol Biotechnol. 2017;55(4):553-61.

https://doi.org/10.17113/ftb.55.04.17.5157

56. Poyato C, Navarro-Blasco I, Calvo MI, Cavero RY, Astiasarán I, Ansorena D. Oxidative stability of O/W and W/O/W emulsions: Effect of lipid composition and antioxidant polarity. Food Res Int. 2013;51(1):132-40. https://doi.org/10.1016/j.foodres.2012.11.032 